\title{
Cancer incidence attributable to red and processed meat consumption in Alberta in 2012
}

\author{
Anne Grundy PhD, Abbey E. Poirier MSc, Farah Khandwala MSc, Alison McFadden BSc, \\ Christine M. Friedenreich PhD, Darren R. Brenner PhD
}

See also www.cmajopen.ca/lookup/doi/10.9778/cmajo.20150068

\section{Abstract}

Background: Consumption of red and processed meats has been associated with an increased risk of colorectal cancer. The purpose of this study was to estimate the proportion and absolute number of cancers in Alberta in 2012 that could be attributed to the consumption of red and processed meat.

Methods: The number and proportion of colorectal cancers in Alberta that were attributable to red and processed meat consumption were estimated using population attributable risk. Relative risks were obtained from the World Cancer Research Fund's 2011 Continuous Update Project on Colorectal Cancer, and the prevalence of red and processed meat consumption was estimated using dietary data from Alberta's Tomorrow Project. Age- and sex-specific colorectal cancer incidence data for 2012 were obtained from the Alberta Cancer Registry.

Results: Among participants in Alberta's Tomorrow Project, $41 \%-61 \%$ of men and $14 \%-25 \%$ of women consumed more than $500 \mathrm{~g}$ of red and processed meat per week, which exceeds World Cancer Research Fund cancer prevention guidelines. For red meat consumption, population attributable risks for colorectal cancer were substantially higher for men (13.6\%-17.9\%) than for women (1.6\%$2.1 \%)$. For processed meat consumption, the population attributable risks were also higher for men $(3.2 \%-4.8 \%)$ than for women $(1.5 \%-2.1 \%)$. Overall, about $12 \%$ of colorectal cancers, or $1.5 \%$ of all cancers, in Alberta in 2012 were attributable to the consumption of red and processed meat.

Interpretation: Red and processed meat consumption is estimated to acount for about $12 \%$ of colorectal cancers in Alberta. Decreasing its consumption has the potential to reduce to Alberta's cancer burden.

\footnotetext{
T n their 2007 report, the World Cancer Research Fund described red meat as "flesh from animals that have more _red than white muscle fibres" and processed meat as "meats (usually red meats) preserved by smoking, curing, or salting, or by the addition of preservatives". ${ }^{1}$ The report determined that there was a "convincing increased risk" for colorectal cancer associated with both red and processed meat consumption on the basis of data from both case-control and cohort studies that provided evidence of a dose-response relationship. ${ }^{1}$ In 2011, the World Cancer Research Fund's Continuous Update Project evaluated updated evidence concerning this relationship and confirmed the 2007 classification. $^{2}$ The World Cancer Research Fund recommends limiting red meat consumption to "less than $500 \mathrm{~g}(18 \mathrm{oz})$ per week, with very little if any to be processed" for the purposes of cancer prevention. ${ }^{1}$ Most recently, in October 2015, the International Agency for Research on Cancer classified processed
}

meat consumption as a Group 1 carcinogen and red meat consumption as a Group 2A (probable) carcinogen as part of their monograph program. ${ }^{3}$ Colorectal cancer was the fourth most common and second leading cause of cancer death in Alberta in 2012. ${ }^{4}$

Previous analyses from the United Kingdom estimated that $21.1 \%$ of colorectal cancers or $2.7 \%$ of all cancers in 2010 could be attributed to red and processed meat consump-

\section{Competing interests: None declared.}

This article has been peer reviewed.

Correspondence to: David Brenner, Darren.Brenner@ albertahealthservices.ca

CMAJ Open 2016. DOI:10.9778/cmajo.20160036 
tion. ${ }^{5}$ Because red and processed meat consumption is a modifiable risk factor, understanding the burden of cancer in Alberta that is attributable to this dietary characteristic will provide useful information concerning the potential impact of changes in meat consumption patterns among Albertans with respect to cancer. Thus, the objective of this study was to quantify the proportion and absolute number of colorectal cancer cases in Alberta that could be attributed to red and processed meat consumption in 2012.

\section{Methods}

This article is part of a series of exposure-specific reports concerning the proportion of cancer cases attributable to modifiable lifestyle and environmental risk factors in the general population of Alberta. The methodologic framework for this series has been previously described. ${ }^{6}$

An adaptation of the method employed by Parkin ${ }^{5}$ was used to estimate the population attributable risks (PARs) for both red and processed meat with respect to colorectal cancer (as well as colon and rectal cancer individually) in Alberta so that the Alberta results could be directly compared with those from the United Kingdom.

\section{Prevalence of exposure}

Information on consumption of both red and processed meat was obtained from data from Alberta's Tomorrow Project. ${ }^{7}$ Alberta's Tomorrow Project is a population-based cohort study conducted in Alberta. ${ }^{7}$ Collection of the data used in the current analysis occurred between 2000 and 2009. Of the 63547 people who received enrollment packages for Alberta's Tomorrow Project, $49 \%$ enrolled. The project is considered to be geographically representative of Alberta, with $75 \%$ of participants living in urban areas. All participants are volunteers. Participation in the cohort involved completing a baseline study questionnaire; 3 months after enrollment into the study, participants completed a diet history questionnaire composed of a cognitive-based food-frequency questionnaire developed by the United States National Cancer Institute as a tool to assess diet over the preceding 12 months. ${ }^{7}$ This questionnaire has been previously validated and is considered comparable to other such questionnaires used in other large cohort studies. ${ }^{8}$ Alberta's Tomorrow Project variables taken from this questionnaire estimated the number of ounces each of red (beef, pork, lamb, veal, venison, liver etc.) and processed (cold cuts, sausage, ham, hot dogs) meat consumed each day. These values were converted to grams per day for analysis. Overall red and processed meat consumption was divided into deciles, and the mean level of consumption, in addition to the proportion of the population in each decile, was calculated for men and women in 4 age groups $(35-44,45-54,55-64, \geq 65 \mathrm{yr})$.

\section{Latency period}

As has been previously described, ${ }^{6}$ we considered the theoretical latency period to be the time between the start of exposure and cancer diagnosis, and the measured latency period to be the time between exposure measurement and cancer diagnosis.
For the analyses described here, we attempted to quantify the measured latency period from existing high-quality cohort studies as the duration of mean follow-up between exposure measurement and cancer diagnosis and to subsequently refer to this simply as the latency period. This process showed mean follow-up times between meat consumption and colorectal cancer incidence of between 10 and 14 years in previously conducted high-quality cohort studies. ${ }^{9-11}$ However, data on meat consumption in Alberta was only available from Alberta's Tomorrow Project data collected between 2000 and 2009, and the 8-year mean latency period in this analysis is slightly shorter than that suggested by cohort studies in the literature.

\section{Statistical analysis}

The relative risks (RRs) for colorectal cancer, as well as colon and rectal cancer individually, with respect to red and processed meat consumption were obtained from the World Cancer Research Fund's 2011 Continuous Update Project on Colorectal Cancer, ${ }^{2}$ an international collaborative group (Appendix 1, available at www.cmajopen.ca/content/4/4/ E768/suppl/DC1, Supplementary Figure 1). As in Parkin's analysis, ${ }^{5}$ the increase in risk for both of these exposures was assumed to be logarithmic relative to meat intake, and the risk per gram $\left(R_{g}\right)$ of meat intake was estimated using equation 1 :

Equation 1: $R_{g}=\ln \left(\mathrm{RR}_{x}\right) / x$

where $x$ represents the exposure level in grams per day of the original RR.

To estimate population attributable risks, the RR of meat consumption in each of the 10 consumption categories was estimated according to equation 2 :

Equation 2: $\mathrm{RR}_{x}=\exp \left(R_{g} \times G_{x}\right)$

where $R_{g}$ represents the risk per gram of meat consumption based on the RR from the Continuous Update Project ${ }^{2}$ and $G_{x}$ represents the consumption of meat per day in consumption category $x$.

Population attributable risks were then estimated within each age-sex group according to the formula used by Parkin ${ }^{5}$ (a variant of Levin's ${ }^{12}$ formula), shown in equation 3:

$$
\text { Equation 3: } \mathrm{PAR}=\Sigma\left(p_{x} \times \mathrm{ERR}_{x}\right) /\left[1+\Sigma\left(p_{x} \times \mathrm{ERR}_{x}\right)\right]
$$

where $p_{x}$ represents the proportion of the population in consumption category $x$, while $\mathrm{ERR}_{x}$ represents the excess relative risk in consumption category $x$, calculated as $\mathrm{RR}_{x}-1$. To estimate the total number of cancers attributable to red and processed meat consumption at each site overall and by agegroup and sex, population attributable risks were applied to cancer incidence data from the Alberta Cancer Registry for 2012. The total proportion of cancer attributable to red and processed meat consumption was estimated as the total number of excess attributable cases across age groups divided by the total number of observed cancers for men, women and men and women combined. 


\section{OPEN}

Research

To estimate $95 \%$ confidence intervals (CIs) related to population attributable risk estimates, Monte Carlo simulation methods were used wherein the RR estimates were drawn from a log-normal distribution, prevalence estimates were drawn from a binomial distribution, and incidence estimates were drawn from a Poisson distribution. Parameters for the distributions were defined by reported point estimates and confidence intervals. We drew 10000 samples. and the 2.5 th and 97.5 th percentiles of the resulting population attributable risk distribution were used as the lower and upper limits of a 95\% CI. Similar techniques were used in previous studies that estimated population attributable risk. ${ }^{13,14}$ Wherever possible and appropriate, these estimations were performed for individual sex and age groups.

\section{Results}

Red and processed meat consumption in grams per day, and the proportion of the population in each of 10 consumption categories by age and sex, are shown in Table 1 and Table 2.
Estimated risks with consumption of red and processed meat and latency periods for population attributable risk calculations are shown in Table 3.

Among Alberta's Tomorrow Project participants, levels of red and processed meat consumption were substantially higher among men than among women in all age groups, although consumption did appear to decrease with age in both sexes (Figure 1). The proportions of people consuming more than $500 \mathrm{~g} /$ week of red and processed meat were highest among those aged 35-44 years (men, 61\%; women, 25\%) and lowest among thosed aged 65 years and older (men, 41\%; women, 14\%).

The higher prevalence of red and processed meat consumption among men than among women translated to elevated estimates of population attributable risk for men, particularly in relation to red meat (Table 4, Table 5). Among men, estimated population attributable risks for colorectal cancer related to red meat consumption ranged from $13.6 \%$ to $17.9 \%$ across age groups; comparable estimates for women ranged from $1.6 \%$ to $2.1 \%$ (Table 4). When colon and rectal cancers were consid-

Table 1: Red meat consumption and the proportion of the population in each of 10 consumption categories, by age and sex

\begin{tabular}{|c|c|c|c|c|c|c|c|c|}
\hline \multirow{3}{*}{$\begin{array}{l}\text { Meat consumption } \\
\text { category, g/d }\end{array}$} & \multicolumn{8}{|c|}{ Age, yr } \\
\hline & \multicolumn{2}{|c|}{$35-44$} & \multicolumn{2}{|c|}{$45-54$} & \multicolumn{2}{|c|}{$55-64$} & \multicolumn{2}{|c|}{$\geq 65$} \\
\hline & $g / d$ & $\%$ & $g / d$ & $\%$ & $g / d$ & $\%$ & $g / d$ & $\%$ \\
\hline \multicolumn{9}{|l|}{ Men } \\
\hline $1:<14.5$ & 8.52 & 2.66 & 8.67 & 3.77 & 9.13 & 4.67 & 8.98 & 5.89 \\
\hline $2: 14.5-21.4$ & 18.27 & 4.00 & 18.09 & 4.36 & 17.97 & 6.31 & 17.94 & 9.11 \\
\hline 3: 21.5-27.9 & 25.06 & 4.92 & 24.58 & 5.52 & 24.80 & 7.53 & 24.92 & 11.58 \\
\hline $4: 28.0-34.2$ & 31.04 & 6.56 & 31.10 & 6.90 & 31.09 & 7.25 & 31.38 & 7.61 \\
\hline $5: 34.3-41.3$ & 37.53 & 7.48 & 37.65 & 7.86 & 37.58 & 8.94 & 38.05 & 9.97 \\
\hline $6: 41.4-49.2$ & 45.54 & 8.40 & 45.60 & 9.43 & 45.00 & 10.20 & 45.51 & 9.75 \\
\hline $7: 49.3-59.2$ & 54.26 & 11.31 & 54.17 & 11.07 & 54.16 & 10.82 & 53.59 & 9.65 \\
\hline 8: 59.3-73.3 & 65.57 & 14.14 & 65.98 & 13.21 & 65.88 & 12.16 & 65.95 & 13.72 \\
\hline 9: 73.4-100.3 & 85.31 & 16.77 & 85.73 & 16.28 & 85.92 & 15.14 & 86.82 & 10.93 \\
\hline $10: \geq 100.4$ & 154.29 & 23.74 & 154.03 & 21.60 & 144.21 & 16.98 & 149.84 & 11.79 \\
\hline Mean & 77.22 & & 73.81 & & 65.00 & & 57.04 & \\
\hline \multicolumn{9}{|l|}{ Women } \\
\hline $1:<14.5$ & 9.28 & 10.22 & 8.95 & 13.57 & 9.31 & 14.86 & 9.07 & 19.20 \\
\hline 2: 14.5-21.4 & 18.05 & 11.48 & 18.07 & 12.17 & 17.92 & 15.03 & 18.02 & 15.79 \\
\hline 3: 21.5-27.9 & 24.86 & 12.01 & 24.71 & 12.22 & 24.66 & 12.34 & 24.87 & 14.67 \\
\hline $4: 28.0-34.2$ & 30.97 & 11.40 & 30.98 & 11.27 & 30.85 & 11.10 & 30.98 & 11.50 \\
\hline $5: 34.3-41.3$ & 37.54 & 12.33 & 37.59 & 11.49 & 37.72 & 10.76 & 37.44 & 10.19 \\
\hline $6: 41.4-49.2$ & 45.07 & 10.46 & 45.22 & 10.28 & 45.28 & 10.71 & 44.69 & 8.70 \\
\hline $7: 49.3-59.2$ & 54.21 & 10.66 & 53.81 & 9.77 & 53.69 & 8.24 & 53.87 & 8.02 \\
\hline 8: 59.3-73.3 & 65.65 & 9.11 & 65.58 & 7.97 & 65.82 & 7.83 & 65.72 & 5.66 \\
\hline 9: 73.4-100.3 & 84.45 & 7.80 & 84.19 & 7.03 & 85.00 & 5.87 & 84.47 & 4.10 \\
\hline $10: \geq 100.4$ & 131.99 & 4.53 & 132.78 & 4.22 & 134.37 & 3.27 & 129.22 & 2.18 \\
\hline Mean & 43.20 & & 40.90 & & 38.41 & & 33.81 & \\
\hline
\end{tabular}


Table 2: Processed meat consumption and the proportion of the population in each of 10 consumption categories, by age and sex

\begin{tabular}{|c|c|c|c|c|c|c|c|c|}
\hline \multirow{3}{*}{$\begin{array}{l}\text { Meat } \\
\text { consumption } \\
\text { category, g/d }\end{array}$} & \multicolumn{8}{|c|}{ Age, yr } \\
\hline & \multicolumn{2}{|r|}{$35-44$} & \multicolumn{2}{|r|}{$45-54$} & \multicolumn{2}{|r|}{$55-64$} & \multicolumn{2}{|r|}{$\geq 65$} \\
\hline & $g / d$ & $\%(95 \% \mathrm{Cl})$ & $g / d$ & $\%(95 \% \mathrm{Cl})$ & $g / d$ & $\%(95 \% \mathrm{Cl})$ & $g / d$ & $\%(95 \% \mathrm{Cl})$ \\
\hline \multicolumn{9}{|l|}{ Men } \\
\hline $1:<1.7$ & 0.88 & 2.7 (2.1-3.3) & 0.92 & $3.9(3.2-4.5)$ & 0.93 & $5.4(4.5-6.3)$ & 0.97 & $6.3(4.8-7.9)$ \\
\hline $2: 1.7-3.1$ & 2.40 & $2.7(2.1-3.2)$ & 2.45 & $3.0(2.5-3.6)$ & 2.45 & $5.5(4.6-6.4)$ & 2.45 & $6.3(4.8-7.9)$ \\
\hline 3: $3.1-4.5$ & 3.67 & $4.7(3.9-5.4)$ & 3.72 & $5.7(5.0-6.5)$ & 3.71 & $8.5(7.4-9.6)$ & 3.66 & $8.0(6.3-9.8)$ \\
\hline $4: 4.5-6.2$ & 5.25 & $6.1(5.2-7.0)$ & 5.24 & $7.6(6.7-8.5)$ & 5.23 & $9.5(8.4-10.7)$ & 5.24 & $9.7(7.8-11.5)$ \\
\hline 5: $6.2-8.2$ & 7.23 & $9.3(8.2-10.3)$ & 7.17 & $9.7(8.8-10.7)$ & 7.25 & $10.4(9.2-11.6)$ & 7.21 & $12.2(10.1-14.3)$ \\
\hline $6: 8.2-11.0$ & 9.59 & $9.7(8.7-10.8)$ & 9.53 & $8.8(7.8-9.7)$ & 9.55 & $10.0(8.8-11.1)$ & 9.61 & $10.6(8.6-12.6)$ \\
\hline $7: 11.1-15.0$ & 12.90 & $12.0(10.8-13.2)$ & 12.79 & $11.9(10.8-12.9)$ & 12.76 & $11.5(10.3-12.8)$ & 12.95 & $13.0(10.8-15.1)$ \\
\hline 8: 15.0-21.5 & 17.96 & $13.9(12.7-15.2)$ & 18.11 & $14.4(13.3-15.6)$ & 18.11 & $12.2(11.0-13.5)$ & 18.23 & $11.5(9.4-13.5)$ \\
\hline $9: 21.5-32.6$ & 26.51 & $16.8(15.4-18.1)$ & 26.83 & $14.6(13.4-15.8)$ & 26.41 & $13.0(11.7-14.3)$ & 26.81 & $11.2(9.2-13.3)$ \\
\hline $10: \geq 32.6$ & 56.94 & $22.1(20.6-23.6)$ & 56.57 & $20.4(19.0-21.7)$ & 54.45 & $13.9(12.5-15.2)$ & 50.70 & $11.2(9.1-13.2)$ \\
\hline Mean g/d & 7.19 & & 6.92 & & 6.27 & & 6.02 & \\
\hline \multicolumn{9}{|l|}{ Women } \\
\hline $1:<1.7$ & 0.97 & $9.7(8.8-10.5)$ & 0.99 & $13.7(12.8-14.5)$ & 1.02 & $16.8(15.7-18.0)$ & 0.96 & $20.0(18.1-22.0)$ \\
\hline $2: 1.7-3.1$ & 2.43 & $8.3(7.5-9.0)$ & 2.41 & $10.9(10.1-11.7)$ & 2.38 & $13.2(12.1-14.2)$ & 2.37 & $14.7(12.9-16.4)$ \\
\hline $3: 3.1-4.5$ & 3.68 & $10.4(9.5-11.2)$ & 3.65 & $12.7(11.8-13.5)$ & 3.66 & $13.6(12.6-14.6)$ & 3.68 & $13.6(11.9-15.3)$ \\
\hline $4: 4.5-6.2$ & 5.24 & $11.1(10.2-11.9)$ & 5.21 & $12.6(11.7-13.4)$ & 5.25 & $12.2(11.2-13.2)$ & 5.17 & $11.9(10.3-13.4)$ \\
\hline 5: 6.2-8.2 & 8 & $12.6(11.7-13.5)$ & 7.16 & $11.9(11.1-12.8)$ & 7.23 & $11.7(10.7-12.7)$ & 7.17 & $9.1(7.7-10.5)$ \\
\hline $6: 8.2-11.0$ & 9.57 & $10.8(10.0-11.7)$ & 9.50 & $9.2(8.4-9.9)$ & 9.56 & $8.1(7.3-8.9)$ & 9.60 & $7.6(6.3-8.9)$ \\
\hline 7: 11.1-15.0 & 12.69 & $10.9(10.0-11.7)$ & 12.83 & $9.3(8.5-10.0)$ & 12.80 & 7.7 (6.9-8.6) & 12.89 & $6.0(4.9-7.2)$ \\
\hline 8: 15.0-21.5 & 17.85 & $10.9(10.0-11.7)$ & 17.93 & $8.0(7.3-8.7)$ & 17.90 & $6.7(5.9-7.4)$ & 17.63 & $6.7(5.5-7.9)$ \\
\hline $9: 21.5-32.6$ & 24.94 & $9.2(8.4-10.1)$ & 26.30 & $7.5(6.8-8.2)$ & 26.11 & $5.4(4.7-6.1)$ & 26.09 & $6.1(4.9-7.3)$ \\
\hline $10: \geq 32.6$ & 49.80 & $6.2(5.5-6.9)$ & 47.89 & $4.3(3.8-4.8)$ & 46.11 & $4.5(3.9-5.2)$ & 47.36 & $4.2(3.2-5.2)$ \\
\hline Mean $\mathrm{g} / \mathrm{d}$ & 5.38 & & 4.78 & & 4.42 & & 4.22 & \\
\hline
\end{tabular}

Table 3: Estimated risks with consumption of red and processed meat and latency periods for calculating population attributable risk

$\begin{array}{llllll}\text { Cancer site } & \text { Sex } & \text { RR estimate } & \text { Units, g/d } & \text { Risk per g/d } & \text { Source* Latency period, yr }\end{array}$

\section{Red meat}

\begin{tabular}{|c|c|c|c|c|c|c|}
\hline Colorectal & Men & 1.28 & 100 & 0.0025 & WCRF $2011^{2}$ & 8 \\
\hline Colorectal & Women & 1.05 & 100 & 0.00049 & WCRF $2011^{2}$ & 8 \\
\hline Colon & Men & 1.00 & 100 & 0 & WCRF $2011^{2}$ & 8 \\
\hline Colon & Women & 1.06 & 100 & 0.00058 & WCRF $2011^{2}$ & 8 \\
\hline Rectum & All & 1.18 & 100 & 0.0017 & WCRF $2011^{2}$ & 8 \\
\hline \multicolumn{7}{|c|}{ Processed meat } \\
\hline Colorectal & Men & 1.11 & 50 & 0.0021 & WCRF $2011^{2}$ & 8 \\
\hline Colorectal & Women & 1.09 & 50 & 0.0017 & WCRF $2011^{2}$ & 8 \\
\hline Colon & Men & 1.38 & 50 & 0.0064 & WCRF $2011^{2}$ & 8 \\
\hline Colon & Women & 1.64 & 50 & 0.0099 & WCRF $2011^{2}$ & 8 \\
\hline Rectum & All & 1.12 & 50 & 0.0023 & WCRF $2011^{2}$ & 8 \\
\hline
\end{tabular}

Note: $\mathrm{RR}=$ relative risk, $\mathrm{WCRF}=$ World Cancer Research Fund.

*Details concerning the meta-analysis that produced the RR found in the 2011 WCRF Continuous Update Project on Colorectal Cancer can be found at www.wcrf.org/sites/ default/files/SLR_colorectal_cancer_2010.pdf 


\section{OPEN}

ered separately, for both men and women, population attributable risk estimates were consistently higher for rectal cancer (Table 4). Differences between men and women were less pronounced when considering population attributable risks associated with processed meat consumption (Table 5), although estimated risk values remained higher for men $(3.2 \%-4.2 \%)$ than for women $(1.5 \%-2.1 \%)$ for colorectal cancer. In contrast to red meat, when colon and rectal cancers attributable to processed meat consumption were considered separately, estimated population attributable risk values were higher for colon than for rectal cancer for both men and women (Table 5).

Overall, $9.5 \%$ of colorectal cancers were estimated to be attributable to red meat consumption and $5.9 \%$ to processed meat consumption (Table 6). This translates to an estimated 181 excess cases of colorectal cancer due to red meat consumption and 54 excess cases due to processed meat consumption. There were substantial differences in the number of estimated excess cases for men and women; among men, 166 excess cases were estimated to be due to red meat consumption and 41 excess cases due to processed meat consumption, whereas comparable values among women were an estimated 15 excess cases for red meat consumption and 13 cases for processed meat consumption (Table 6). Overall,

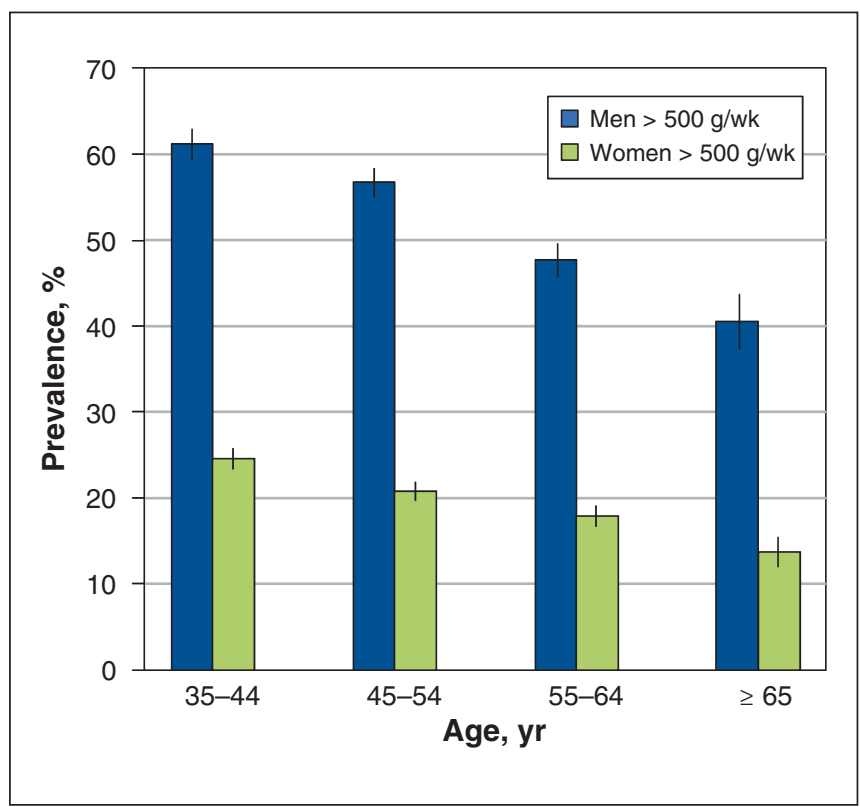

Figure 1: Proportion of men and women in the Alberta's Tomorrow Project cohort who consume more than 500 grams of red and processed meat per week, by age group.

Table 4: Cancer cases and proportions attributable to red meat intake in Alberta, 2012

\begin{tabular}{|c|c|c|c|c|c|c|c|c|c|c|}
\hline \multirow[b]{2}{*}{$\begin{array}{l}\text { Age at } \\
\text { exposure, } \\
y r\end{array}$} & \multirow[b]{2}{*}{$\begin{array}{c}\text { Age at } \\
\text { outcome, yr }\end{array}$} & \multicolumn{3}{|c|}{ Colorectal } & \multicolumn{3}{|c|}{ Colon } & \multicolumn{3}{|c|}{ Rectum } \\
\hline & & $\begin{array}{c}\text { Total } \\
\text { observed } \\
\text { cases }\end{array}$ & $\begin{array}{l}\text { PAR, \% } \\
(95 \% \mathrm{Cl})\end{array}$ & $\mathrm{EAC}^{\star}$ & $\begin{array}{c}\text { Total } \\
\text { observed } \\
\text { cases }\end{array}$ & $\begin{array}{l}\text { PAR, \% } \\
(95 \% \mathrm{Cl})\end{array}$ & $E A C^{*}$ & $\begin{array}{l}\text { Total } \\
\text { observed } \\
\text { cases }\end{array}$ & $\begin{array}{l}\text { PAR, \% } \\
(95 \% \mathrm{Cl})\end{array}$ & $\mathrm{EAC}^{*}$ \\
\hline \multicolumn{11}{|l|}{ Men } \\
\hline $35-44$ & $43-52$ & 96 & $17.9(0-67.3)$ & 17 & 38 & $8.5(0-18.5)$ & 3 & 58 & $12.3(0-24.7)$ & 7 \\
\hline $45-54$ & $53-62$ & 280 & $17.2(0-65.6)$ & 48 & 139 & $8.2(0-17.8)$ & 11 & 141 & $11.8(0-23.7)$ & 17 \\
\hline $55-64$ & $63-72$ & 320 & $15.3(0-60.4)$ & 49 & 177 & $7.2(0-15.8)$ & 13 & 143 & $10.4(0-21.1)$ & 15 \\
\hline$\geq 65$ & $\geq 73$ & 383 & $13.6(0-56.1)$ & 52 & 260 & $6.4(0-14.1)$ & 17 & 123 & $9.2(0-19.2)$ & 11 \\
\hline Total & & 1079 & & 166 & 614 & & 44 & 465 & & 50 \\
\hline \multicolumn{11}{|l|}{ Women } \\
\hline $35-44$ & $43-52$ & 81 & $2.1(0-14.4)$ & 2 & 42 & $4.8(0-10.7)$ & 2 & 39 & $7(0-14.5)$ & 3 \\
\hline $45-54$ & $53-62$ & 181 & $2.0(0-13.4)$ & 4 & 105 & $4.6(0-10.2)$ & 5 & 76 & $6.6(0-13.9)$ & 5 \\
\hline $55-64$ & $63-72$ & 202 & $1.9(0-13.0)$ & 4 & 125 & $4.3(0-9.5)$ & 5 & 77 & $6.3(0-13.0)$ & 5 \\
\hline$\geq 65$ & $\geq 73$ & 356 & $1.6(0-11.5)$ & 6 & 265 & $3.8(0-8.4)$ & 10 & 91 & $5.5(0-11.5)$ & 5 \\
\hline Total & & 820 & & 15 & 537 & & 22 & 283 & & 18 \\
\hline \multicolumn{11}{|l|}{ Total† } \\
\hline $35-44$ & $43-52$ & 177 & 10.7 & 19 & 80 & 6.6 & 5 & 97 & 10.2 & 10 \\
\hline $45-54$ & $53-62$ & 461 & 11.2 & 52 & 244 & 6.6 & 16 & 217 & 10 & 22 \\
\hline $55-64$ & $63-72$ & 522 & 10.1 & 53 & 302 & 6 & 18 & 220 & 9 & 20 \\
\hline$\geq 65$ & $\geq 73$ & 739 & 7.8 & 58 & 525 & 5.1 & 27 & 214 & 7.6 & 16 \\
\hline Total & & 1899 & & 181 & 1151 & & 66 & 748 & & 68 \\
\hline
\end{tabular}


Table 5: Cancer cases and proportions attributable to processed meat intake in Alberta, 2012

\begin{tabular}{|c|c|c|c|c|c|c|c|c|c|c|}
\hline \multirow[b]{2}{*}{$\begin{array}{l}\text { Age at } \\
\text { exposure, } \\
y r\end{array}$} & \multirow[b]{2}{*}{$\begin{array}{c}\text { Age at } \\
\text { outcome, } \\
\text { yr }\end{array}$} & \multicolumn{3}{|c|}{ Colorectal } & \multicolumn{3}{|c|}{ Colon } & \multicolumn{3}{|c|}{ Rectum } \\
\hline & & $\begin{array}{c}\text { Total } \\
\text { observed } \\
\text { cases }\end{array}$ & $\begin{array}{l}\text { PAR, \% } \\
(95 \% \mathrm{CI})\end{array}$ & EAC & $\begin{array}{c}\text { Total } \\
\text { observed } \\
\text { cases }\end{array}$ & $\begin{array}{c}\text { PAR, \% } \\
(95 \% \mathrm{Cl})\end{array}$ & EAC & $\begin{array}{c}\text { Total } \\
\text { observed } \\
\text { cases }\end{array}$ & $\begin{array}{l}\text { PAR, \% } \\
(95 \% \mathrm{Cl})\end{array}$ & $\mathrm{EACb}$ \\
\hline \multicolumn{11}{|l|}{ Men } \\
\hline $35-44$ & $43-52$ & 96 & $4.8(0-16.0)$ & 5 & 38 & $9.9(5.7-13.9)$ & 4 & 58 & $5.2(0-11.2)$ & 3 \\
\hline $45-54$ & $53-62$ & 280 & $4.5(0-15.5)$ & 13 & 139 & $9.3(5.3-13.3)$ & 13 & 141 & $4.9(0-10.5)$ & 7 \\
\hline $55-64$ & $63-72$ & 320 & $3.6(0-12.7)$ & 12 & 177 & $7.5(4.2-10.7)$ & 13 & 143 & $3.9(0-8.4)$ & 6 \\
\hline$\geq 65$ & $\geq 73$ & 383 & $3.2(0-11.0)$ & 12 & 260 & $6.6(3.8-9.5)$ & 17 & 123 & $3.5(0-7.4)$ & 4 \\
\hline Total & & 1079 & & 41 & 614 & & 47 & 465 & & 20 \\
\hline \multicolumn{11}{|l|}{ Women } \\
\hline $35-44$ & $43-52$ & 81 & $2.1(0-6.9)$ & 2 & 42 & $5.1(2.8-7.4)$ & 2 & 39 & $2.70-5.7)$ & 1 \\
\hline $45-54$ & $53-62$ & 181 & $1.7(0-5.9)$ & 3 & 105 & $4.3(2.4-6.1)$ & 4 & 76 & $2.2(0-4.9)$ & 2 \\
\hline $55-64$ & $63-72$ & 202 & $1.5(0-5.2)$ & 3 & 125 & $3.9(2.2-5.6)$ & 5 & 77 & $2.0(0-4.4)$ & 2 \\
\hline$\geq 65$ & $\geq 73$ & 356 & $1.5(0-5.1)$ & 5 & 265 & $3.7(2.1-5.4)$ & 10 & 91 & $2.0(0-4.2)$ & 2 \\
\hline Total & & 820 & & 13 & 537 & & 21 & 283 & & 6 \\
\hline \multicolumn{11}{|l|}{ Total† } \\
\hline $35-44$ & $43-52$ & 177 & 3.6 & 6 & 80 & 7.4 & 6 & 97 & 4.2 & 4 \\
\hline $45-54$ & $53-62$ & 461 & 3.4 & 16 & 244 & 7.1 & 17 & 217 & 4 & 9 \\
\hline 55-64 & $63-72$ & 522 & 2.8 & 15 & 302 & 6 & 18 & 220 & 3.3 & 7 \\
\hline$\geq 65$ & $\geq 73$ & 739 & 2.4 & 18 & 525 & 5.1 & 27 & 214 & 2.8 & 6 \\
\hline Total & & 1899 & & 54 & 1151 & & 68 & 748 & & 26 \\
\hline
\end{tabular}

we estimate that $1.1 \%$ of all cancers in Alberta can be attributed to red meat consumption and $0.3 \%$ to processed meat consumption.

\section{Interpretation}

Overall, 181 colorectal cancer cases were estimated to be attributable to red meat consumption and 54 to processed meat consumption, which corresponds to about $1.5 \%$ of all cancers in Alberta. The previous analysis by Parkin estimated that $3.5 \%$ of cancers in men and $1.9 \%$ of cancers in women ( $2.7 \%$ overall) diagnosed in the UK in 2010 could be attributed to red and processed meat consumption. ${ }^{5}$ These proportions are substantially higher than those we estimated for cancer in Alberta. One explanation for these differences could be that the reported levels of meat consumption among participants in Alberta's Tomorrow Project are substantially lower than those reported in the UK. ${ }^{5}$ These differences could reflect real differences in meat consumption patterns between Alberta and the UK, but could also be the result of differences in the ages of the populations in which the dietary data were measured in the 2 studies. In Parkin's analysis, data on red and processed meat consumption were obtained from the National Diet and Nutrition Survey, a cross-sectional popula- tion survey in the UK, and Parkin included data from ages 19-64 years. ${ }^{5,15}$ In contrast, our analysis used data from Alberta's Tomorrow Project, which only included people aged 35 years and older. Given that in the UK data the mean red and processed meat consumption levels were highest for participants aged 19-34 years, particularly among men, the exclusion of younger people in our analysis could have led to underestimates of overall levels of meat consumption in Alberta and thus partially account for observed differences in estimated population attributable risks.

A recent study from Australia estimated the population attributable risks related to red and processed meat consumption for colorectal cancer ${ }^{16}$ using similar methods to Parkin. ${ }^{5}$ The findings from Nagle and colleagues ${ }^{16}$ were also similar to those of Parkin, ${ }^{5}$ with an estimated $2.8 \%$ of cancers in men and $1.7 \%$ of cancers in women (2.3\% of cancers overall) in Australia in 2010 attributable to red and processed meat consumption. Similar to the work of Parkin, this Australian study used data from a national population survey to estimate meat consumption, which could account for the difference from our results.

\section{Limitations}

In addition to including only people over the age of 35 years, participants in Alberta's Tomorrow Project are volunteers, 


\section{OPEN}

\begin{tabular}{|c|c|c|c|c|c|c|c|c|c|}
\hline \multirow[b]{2}{*}{ Cancer site† } & \multicolumn{3}{|c|}{ Total } & \multicolumn{3}{|c|}{ Men } & \multicolumn{3}{|c|}{ Women } \\
\hline & $\begin{array}{l}\text { Observed } \\
\text { casesł }\end{array}$ & $\begin{array}{l}\text { Excess } \\
\text { attributable } \\
\text { cases§ }\end{array}$ & $\begin{array}{c}\% \\
\text { Attributableף }\end{array}$ & $\begin{array}{l}\text { Observed } \\
\text { cases } \ddagger\end{array}$ & $\begin{array}{l}\text { Excess } \\
\text { attributable } \\
\text { cases§ }\end{array}$ & $\begin{array}{c}\% \\
\text { Attributable }\end{array}$ & $\begin{array}{l}\text { Observed } \\
\text { cases } \ddagger\end{array}$ & $\begin{array}{l}\text { Excess } \\
\text { attributable } \\
\text { cases§ }\end{array}$ & $\begin{array}{c}\% \\
\text { Attributableף }\end{array}$ \\
\hline \multicolumn{10}{|l|}{ Red meat } \\
\hline Colorectum & 1899 & 181 & 9.5 & 1079 & 166 & 15.4 & 820 & 15 & 1.8 \\
\hline Colon & 1151 & 66 & 5.7 & 614 & 44 & 7.1 & 537 & 22 & 4.1 \\
\hline Rectum & 748 & 68 & 9 & 465 & 50 & 10.7 & 283 & 18 & 6.2 \\
\hline $\begin{array}{l}\text { All associated } \\
\text { cancers }^{\star *}\end{array}$ & 1899 & 181 & 9.5 & 614 & 166 & 15.4 & 537 & 15 & 1.8 \\
\hline All cancers†† & 15836 & 181 & 1.1 & 8155 & 166 & 2.0 & 7681 & 15 & 0.2 \\
\hline \multicolumn{10}{|c|}{ Processed meat } \\
\hline Colorectum & 1899 & 54 & 2.9 & 1079 & 41 & 3.8 & 820 & 13 & 1.6 \\
\hline Colon & 1151 & 68 & 5.9 & 614 & 47 & 7.6 & 537 & 21 & 4.0 \\
\hline Rectum & 748 & 26 & 3.5 & 465 & 20 & 4.3 & 283 & 6 & 2.2 \\
\hline $\begin{array}{l}\text { All associated } \\
\text { cancers }^{\star \star}\end{array}$ & 1899 & 54 & 2.9 & 1079 & 41 & 3.8 & 537 & 13 & 1.6 \\
\hline All cancers†† & 15836 & 54 & 0.3 & 8155 & 41 & 0.5 & 7681 & 13 & 0.2 \\
\hline \multicolumn{10}{|c|}{$\begin{array}{l}\text { *Red and processed meat consumption data for Alberta from Alberta's Tomorrow Project cohort, in which a diet history questionnaire was used to estimate the number of } \\
\text { ounces of each of red (beef, pork, lamb, veal, venison, liver etc.) and processed (cold cuts, sausage, ham, hot dogs) meat consumed each day. } \\
\text { tCancer incidence data obtained from the Alberta Cancer Registry. Data from } 2012 \text { were used for observed cancer cases for all cancer sites. } \\
\text { †Number of observed cancer cases in Alberta in } 2012 \text { at individual cancer sites. } \\
\text { \$Number of cancer cases at individual cancer sites that can be attributed to red and processed meat consumption. } \\
\text { १Proportion of cancers at individual cancer sites attributable to red and processed meat consumption. Calculated as excess attributable cases/observed cases. } \\
{ }^{* *} \text { Represents all cancers with a known association with red and processed meat consumption as listed in table. These values represent colorectal cancer, because colon } \\
\text { and rectal cancers are subsets of this type. } \\
\text { ††Represents all incident cancers in Alberta in } 2012 \text { in all age groups. }\end{array}$} \\
\hline
\end{tabular}

such that participants may not accurately represent red and processed meat consumption levels in Alberta. Specifically, although participants are geographically representative of the province of Alberta, there may be differences in dietary patterns between participants and nonparticipants, presenting a risk of volunteer bias. For example, if people who eat more red and processed meats systematically chose not to enroll in the cohort, consumption levels estimated in the project's data would be underestimates and could lead to underestimation of population attributable risks.

Data published by Cancer Care Ontario from the Canadian Health Measures Survey estimated that the proportions of both men and women exceeding the $500 \mathrm{~g} /$ week guideline for red and processed meat consumption were much lower in Canada as a whole than as estimated for participants in Alberta's Tomorrow Project. ${ }^{17}$ This difference could suggest that Albertans consume more red and processed meat than the general Canadian population or could be due to differences in the techniques used to quantify consumption across these 2 surveys. Dietary data for participants in Alberta's Tomorrow Project were obtained from a food-frequency questionnaire, and intake of red and processed meat in grams per day was converted to grams per week. In contrast, the Canadian Health Measures Survey used 3 questions on the number of times per year that participants consumed different types of red and pro- cessed meat, with the total number of times per year converted to times per week, where 1 occasion of consumption was considered 1 serving or $75 \mathrm{~g} .{ }^{17}$ If "number of times" were not equivalent to "number of servings," the consumption patterns reported by the Canadian Health Measures Survey would be less accurate than those from Alberta's Tomorrow Project and thus cannot be used to reasonably examine the potential for either over or underestimation of consumption. Consequently, the extent to which volunteer bias in Alberta's Tomorrow Project data may have led to underestimates of population attributable risk cannot be quantified.

The use of $95 \%$ CIs around our estimates of population attributable risk to quantify their precision is a strength of our analysis, particularly in comparison to similar studies that have not estimated $95 \%$ CIs. ${ }^{5}$ However, these $95 \%$ CIs also highlight the lack of precision around our estimates (Table 4, Table 5). Specifically, although we estimate that 181 cases of colorectal cancer are attributable to red meat consumption, this estimate could range from 0 to 759. Similarly, although we estimate 54 colorectal cancer cases are attributable to processed meat consumption, this estimate could range from 0 to 157 . These upper estimates would correspond to up to $4.8 \%$ of cancers attributable to red meat consumption and $1.0 \%$ to processed meat consumption. As such, the lack of precision of our estimates of population attributable risk is a limitation of our analysis. 
Although our estimates of population attributable risk provide an estimate of the potential cancer burden in Alberta that is due to the consumption of red and processed meat, we must also consider the multifactorial cause of colorectal cancer when interpreting these results. As previously described, ${ }^{6}$ our series of analyses of population attributable risks for Alberta did not attempt to account for potential interactions between risk factors within cancer sites, such that some of the cancer cases that we attribute to excess red and processed meat consumption might in fact be attributable to the interaction between meat consumption and other risk factors, such as smoking or excess body weight.

\section{Conclusion}

We estimate red and processed meat consumption to account for about $12 \%$ of cases of colorectal cancer and about $1.5 \%$ of all cancers in Alberta. About one-half of the men and onequarter of the women participating in Alberta's Tomorrow Project exceed the World Cancer Research Fund's 500 g/ week recommendation for the consumption of red and processed meat. ${ }^{1}$ If the consumption levels reported among project participants are representative of Alberta as a whole, reducing red and processed meat consumption in the Alberta population could reduce the incidence of colorectal cancer, one of the most common types of cancer in Alberta.

\section{References}

1. World Cancer Research Fund /American Institute for Cancer Research. Food, nutrition, physical activity, and the prevention of cancer: a global perspective. Washington (DC): American Institute for Cancer Research; 2007.

2. World Cancer Research Fund. Continuous update project report. food, nutrition, physical activity, and prevention of colorectal cancer. London (UK): World Cancer Research Fund; 2011

3. Bouvard V, Loomis D, Guyton KZ, et al. Carcinogenicity of consumption of red and processed meat. Lancet Oncol 2015;16:1599-600.

4. Surveillance \& reporting: 2012 report on cancer statistics in Alberta. Edmonton (AB): CancerControl AB, Alberta Health Services; 2015.

5. Parkin DM. 5. Cancers attributable to dietary factors in the UK in 2010. II. Meat consumption. Br 7 Cancer 2011;105(Suppl 2):S24-6.

6. Grundy A, Friedenreich CM, Poirier AE, et al. A methodologic framework to evaluate the number of cancers attributable to lifestyle and environment in Alberta, Canada. CMAJ Open 2016;3:E471-78.

7. Bryant H, Robson PJ, Ullman R, et al. Population-based cohort development in Alberta, Canada: a feasiblity study. Chronic Dis Can 2006;27:51-9.

8. Subar AF, Thompson FE, Kipnis V, et al. Comparative validation of the Block, Willett, and National Cancer Institute food frequency questionnaires : the Eating at America's Table Study. Am 7 Epidemiol 2001;154:1089-99.

9. Ruder EH, Thiébaut ACM, Thompson FE, et al. Adolescent and mid-life diet: risk of colorectal cancer in the NIH-AARP Diet and Health Study. Am 7 Clin Nutr 2011;94:1607-19.

10. Ollberding NJ, Wilkens LR, Henderson BE, et al. Meat consumption, heterocyclic amines and colorectal cancer risk: the Multiethnic Cohort Study. Int 7 Cancer 2012;131:E1125-33.
11. Egeberg R, Olsen A, Christensen J, et al. Associations between red meat and risks for colon and rectal cancer depend on the type of red meat consumed. $\mathcal{F}$ Nutr 2013;143:464-72.

12. Levin ML. The occurrence of lung cancer in man. Acta Unio Int Contra Cancrum 1953;9:531-41.

13. Renehan AG, Soerjomataram I, Tyson M, et al. Incident cancer burden attributable to excess body mass index in 30 European countries. Int 7 Cancer 2010;126:692-702.

14. Lee I-M, Shiroma EJ, Lobelo F, et al. Effect of physical inactivity on major non-communicable diseases worldwide: an analysis of burden of disease and life expectancy. Lancet 2012;380:219-29.

15. National Diet and Nutrition Survey. London (UK): Food Standards Agency; 2011. Available: http://tna.europarchive.org/20110116113217/http://www. food.gov.uk/science/dietarysurveys/ndnsdocuments/ (accessed 2015 Dec. 1)

16. Nagle CM, Wilson LF, Hughes MCB, et al. Cancers in Australia in 2010 attributable to the consumption of red and processed meat. Aust N Z 7 Public Health 2015;39:429-33.

17. Cancer risk factors in Ontario: bealthy weights, bealthy eating and active living. Toronto: Cancer Care Ontario; 2015.

Affiliations: Department of Cancer Epidemiology and Prevention Research (Grundy, Poirier, Khandwala, McFadden, Friedenreich, Brenner), CancerControl Alberta, Alberta Health Services; Department of Oncology (Friedenreich, Brenner), Cumming School of Medicine, University of Calgary; Department of Community Health Sciences (Friedenreich, Brenner), Cumming School of Medicine, University of Calgary, Calgary, Alta.

Contributors: Christine Friedenreich and Darren Brenner were responsible for the study conception. Anne Grundy, Christine Friedenreich, Darren Brenner, Farah Khandwala and Abbey Poirier contributed substantially to the study design and interpretation of the data. Farah Khandwala completed the analysis. Alison McFadden and Anne Grundy were responsible for acquisition of the data. Abbey Poirier, Anne Grundy, Christine Friedenreich, Farah Khandwala, Alison McFadden and Darren Brenner prepared the manuscript, gave final approval of this version to be published and agreed to be guarantors of the work.

Acknowledgements: This project was funded by the Alberta Cancer Prevention Legacy Fund. Dr Christine Friedenreich is supported by an Alberta Innovates-Health Solutions Health Senior Scholar Award and the Alberta Cancer Foundation Weekend to End Women's Cancers Breast Cancer Chair at the University of Calgary. Dr. Darren Brenner is supported by a Capacity Development Award in Cancer Prevention from the Canadian Cancer Society Research Institute (703917). The authors thank Dr. Laura McDougall from the Alberta Cancer Prevention Legacy Fund for her support and guidance. The authors also thank Bethany Kaposhi and Lorraine Shack from the Alberta Cancer Registry for providing cancer incidence data. The authors are grateful for access to data from Alberta's Tomorrow Project. Alberta's Tomorrow Project is only possible due to the commitment of its research participants, its staff and its funders: Alberta Cancer Foundation, Canadian Partnership Against Cancer, Alberta Cancer Prevention Legacy Fund (administered by Alberta Innovates - Health Solutions) and substantial in kind funding from Alberta Health Services. The views expressed herein represent the views of the author(s) and not of Alberta's Tomorrow Project or any of its funders.

Supplemental information: For reviewer comments and the original submission of this manuscript, please see www.cmajopen.ca/content/4/4/ E768/suppl/DC1 